\title{
Mental Health of Employed and Unemployed People in Ahmedabad
}

\author{
Jain Ashika ${ }^{1}$, Dr. S. M. Kaji ${ }^{2}$
}

\section{ABSTRACT:}

The present study examined the effects of mental health of employed and unemployed people in Ahmedabad. The sample consisted of 120 people out of which 60 were employed people and 60 were unemployed people. For this purpose of investigation 'Mental Health Analysis Inventory' by A. B. Jansari, Harkant Badami, Charulata Badami was used. The data obtained were analyzed through ' $t$ ' test to know the mean difference between the two groups. The result shows that there is no significant difference in mental health of employed and unemployed people and employed male and female in Ahmedabad. There is significant difference in mental health of unemployed male and female people at 0.05 Levels.

Keywords: Mental health, Employed, Unemployed, Male, Female, Ahmedabad

Health is the level of functional or metabolic efficiency of a living being. In humans, it is the general condition of a person's mind, body and spirit, usually meaning to be free from illness, injury or pain (as in "good health" or "healthy"). The World Health Organization (WHO) defined health in its broader sense in 1946 as "a state of complete physical, mental, and social well-being and not merely the absence of disease or infirmity"(WHO1948, 2006). Although this definition has been subject to controversy, in particular as lacking operational value and because of the problems created by use of the word "complete", it remains the most enduring

(Jadad2008). Classification systems such as the WHO Family of International Classifications, including the International Classification of Functioning, Disability and Health (ICF) and the International Classification of Diseases (ICD), are commonly used to define and measure the components of health. Mental health is about the ability to work and study to realize your full potential, cope with day-to-day life stresses, be involved in your community, and live your life in a free and satisfying way. A person who has good mental health has good emotional and social well-being and the capacity to cope with change and challenges. Mental health problems can affect your feelings, thoughts and actions, and cause difficulties in your everyday activities, whether at school, at work, or in relationships.

${ }^{1}$ U.G.Student, Department of Psychology,L.D. Arts College, Ahemadabad

${ }^{2}$ Associate Professor, Department of Psychology,L.D. Arts College, Ahemadabad

(C) 2015 I J Ashika, S Kaji; licensee IJIP. This is an Open Access Research distributed under the terms of the Creative Commons Attribution License (http://creativecommons.org/licenses/by/2.0), which permits unrestricted use, distribution, and reproduction in any Medium, provided the original work is properly cited. 


\section{Mental health problems:}

Feeling down, tense, angry or anxious are all normal emotions, but when these feelings persist for long periods of time, or if they begin to interfere with daily life, they may become mental health problems. Most mental health problems are not very severe or long-lasting. However, it is important to get support from your friends and family, and to ask for help early, for example by visiting your local doctor (general practitioner - GP) or your local headspace Centre.

Mental illness Mental illness can occur at any age, but anxiety disorders and depression are quite common problems for young people Mental illness can affect your thoughts, feelings, actions and memory. A mental illness is usually longer-lasting than mental health problems, and causes more distress and disruption to life. There are a number of mental illnesses.In the present study, the aim of the researchers is to compare the mental health level of employed and unemployed people in ahmedabad.

\section{OBJECTIVES}

1. To study differences between employed and unemployed people in relation to their mental health.

2. To study differences between employed male and female in relation to their mental health.

3. To study differences between unemployed male and female in relation to their mental health.

\section{HYPOTHESES}

1. There is no significant difference between employed and unemployed people of mental health.

2. There is no significant difference between employed male and female of mental health.

3. There is no significant difference between unemployed male and female of mental health.

\section{METHOD}

\section{Sample:}

The sample for the present study in Ahmedabad120 employed and unemployed people was Selected.60 were taken from employed people and 60 were taken from unemployed people.

\section{Tool:}

To obtain data, "Mental Health Analysis Inventory" by A. B. Jansari, HarkantBadami and CharulataBadami (2011)was used for the purpose of study. The inventory consists of 100 items with yes/no response pattern. The test-retest reliability score of this test 0.92 and split half 
reliability score this of inventory is 0.90 . Validity of this test was seen to be 0.71 which significant at 0.01 level.

\section{Procedure}

The collection of data was spread over a period of 20 days. The researcher personally visited the selected employed and unemployed in Ahmedabad. On the schedule date the researcher meet the employed and unemployed people and made clear to them the purpose of administration. The researcher sought their co-operation.

The instructions were explained by the researcher and the doubts were clarified. They were assured that their response will be used for research purpose only and will be kept confidential. They were suggested to give free frank and honest responses without any hesitation. The scales were administered to the people. The scales were collected only after they were responded by the subject. After the completion of the administration, the investigator conveyed her gratitude and thanks to the all subject for their kind co-operation. The raw scores were statistically analysed in terms of means; standard deviation and t-test were used to compare mental health level of the employed and unemployed people and relation to their Gender.

\section{RESULTS AND DISCUSSION}

The main objective of present study was to carry out the study of mental health level among employed and unemployed people. In it statistical' $t$ ' method was used. Results discussion of present study is as under:

Table-1 Mean, SD, SED and't' scores of mental health of employed and unemployed people

\begin{tabular}{|lccc|}
\hline Group $\quad \mathrm{N}$ & Mean & \multicolumn{2}{c|}{ SD SE SED 't'Sign. } \\
\hline Employed60 & 64.82 & 11.84 & $1.543 .360 .68 \mathrm{NS}$ \\
Unemployed60 & 62.55 & 23.24 & 2.99 \\
& & & \\
& & & \\
\hline
\end{tabular}

Non-significant. $(0.05=1.98)$

Table-1 depicts that the value of mean and SD of mental health of employed were 64.82 and 11.84 respectively and those of unemployed were 62.55 and 23.24 respectively. The ' $t$ ' value came out to be 0.68 which is non-significant, Thus the null hypothesis, number 1 , which states "there is no significant difference between employed and unemployed of mental health" was accepted. It means that the mental health ofemployed and unemployed people is of the same level. 
Table-2 Mean, SD, SED and ' $t$ ' scores of mental health of employed male and female

\begin{tabular}{|lccccccc|}
\hline Group & $\mathrm{N}$ & Mean & $\mathrm{SD}$ & $\mathrm{SE}$ & $\mathrm{SED}$ & ' $\mathrm{t}$ ' & Sign. \\
\hline Employed-Male & 30 & 65.23 & 11.24 & 2.05 & 3.04 & 0.27 & $\mathrm{NS}$ \\
Employed-Female & 30 & 64.4012 .34 & 2.25 & & & \\
& & & & & & & \\
\hline
\end{tabular}

Non-Significant.(0.05=1.98)

Table-2 depicts that the value of mean and SD of mental health of employed male were 65.23 and 11.24 respectively and those of employed female were 64.40 and 12.34 respectively. The ' $t$ ' value came out to be 0.27 which is non-significant, Thus the null hypothesis, number 2 , which states "there is no significant difference between employed male and female of mental health" was accepted. It means that the mental health ofemployed male and female is of the same level.

Table-3 Mean, SD, SED and 't' scores of mental health of unemployed male and female

\begin{tabular}{|c|c|c|c|c|c|c|}
\hline Group & $\mathrm{N}$ & Mean & SD & SED & ' $t$ ' & Sign. \\
\hline Employed-Male & 30 & 64.47 & \multicolumn{2}{|c|}{$13.151 .712 .951 .41 \mathrm{NS}$} & & \\
\hline Employed-Female & 30 & 64.63 & 09.3 & 2.40 & & \\
\hline
\end{tabular}

Non- Significant.

Table-3 depicts that the value of mean and SD of mental health of unemployed male were 64.47 and 13.15 respectively and those of unemployed female were 64.63 and 09.35respectively. The ' $t$ ' value came out to be 1.41 which is non-significant, Thus the null hypothesis, number 3 , which states "there is no significant difference between unemployed male and female of mental health" was accepted. It means that the mental health ofunemployed male and female is of the same level.

\section{CONCLUSION}

Major findings of the present study are,

1. There is no significant difference between employed and unemployed people in Ahmedabad.

2. There is no significant difference between employed male and female in Ahmedabad.

3. There is no significant difference between unemployed male and female in Ahmedabad. 


\section{REFERENCES}

1. Angell M 2008. The ethics of clinical research in the Third World. [Editorial] New England Journal of Medicine, 337(12): 847-849.

2. Beigh S.H. 2006. Assessment of Nutritional Knowledge among Women Residing in University Campus.Master's Dissertation, Unpublished Ellen F, Giovanni B, Paola R, Wesley KT, Kreamer HC 2011

3. JansariAshvin, BadamiHarkant and BadamiCharulatta (2011), 'Mental Health Analysis inventory' BharatiManomapan center, Ahmedabad.

4. M.Subramanian and Dr. S.Krishnamurthy 'A Study of mental health of post graduate commerce students and their achievement in commerce subject, 'Indian Streams Research Journal (April; 2012)

5. Nandoliya, H.G. (2010).“A study of Mental Health, Personality and Job satisfaction of Higher

6. Secondary school Teacher in relation to sex habitat types of school and faculty" page: (216, 43-63, 65-71, 90-102,384)

7. Phichaiprome, J. (1999).An Investigation of the factors influencing Mental Health of Teachers at Lamphun Municipal Schools, Unpublished M. Ed. Dissertation in Educational Psychology and Guidance, Lamphun University.

8. Predictors and moderators of time to remission of major pharmacotherapy. Psychological Medicine, 41(1): 151-162. Galloway R, Dusch E, Elder L, Achadi E, Grajeda R 2002

9. Singh, A and Walia.G.S. (2004) Health and Physical Education, Vinod Publications Ludhiana.

10. UNESCO (1972).Learning to be, The World of Education - today and tomorrow International Commission on the Development of Education, Paris.30

11. Srivastava, S. K., Prasad, Deepeshchand and kumar, vipin, (1999), 'A study of mental health of Hindi and English medium students'. J. Edu. Res. Extn. , 36 (3): 23-28

12. World Health Organization 1948.WHO Definition of Health, Geneva: WHO 